\title{
Peak inspiratory pressure requirements in infants born weighing less than $750 \mathrm{~g}$
}

\author{
Keith D Foote, Alexander H Hoon Jr, Sam Sheps, Narajeeva R Gunawardene,
} Ruth Hershler, Margaret R Pendray

\begin{abstract}
The possibility that peak inspiratory pressure requirements or the arterial:alveolar oxygen ratio can predict the clinical outcome in infants weighing $<750 \mathrm{~g}$ at birth was explored in a consecutive series. Nine of 10 infants (90\%) with a peak inspiratory pressure requirement of more than $18 \mathrm{~cm} \mathrm{H}_{2} \mathrm{O}$ at 48 hours or more than $16 \mathrm{~cm} \mathrm{H}_{2} \mathrm{O}$ at 72 hours from age subsequently died later of respiratory causes (defined as death after 72 hours of pulmonary interstitial emphysema, bronchopulmonary dysplasia, or cor pulmonale). Twenty of 21 remaining infants (95\%) survived until discharge. Using these data a 95th centile for peak inspiratory pressure requirement during the first 72 hours of life was constructed. The potential value of this centile in predicting later death of respiratory causes was examined in a separate series. Twelve of 15 infants (80\%) whose peak inspiratory pressure requirements remained below the 95th centile, or were not ventilated $(n=6)$, survived. In contrast, 11 of $12(92 \%)$ infants whose requirements crossed the 95th centile died later of respiratory causes. The infants who died had more radiological changes and higher mean arterial carbon dioxide pressure than survivors suggesting that the severity of the initial lung disease rather than the way that ventilation was managed determined prognosis. Peak inspiratory pressure requirement was more useful than arterial:alveolar oxygen ratio in clearly distinguishing between survivors and infants who died later of respiratory causes.
\end{abstract}

\section{University of}

British Columbia,

Vancouver,

Canada

Division of Neonatology,

Department of

Paediatrics,

British Columbia's

Children's Hospital

Keith D Foote

Alexander $\mathrm{H}$ Hoon $\mathrm{Jr}$

Narajeeva R Gunawardene

Margaret R Pendray

Department of

Health Care

and Epidemiology

Sam Sheps

Ruth Hershler

Correspondence to: Dr Keith D Foote, Department of Paediatrics, Kepartment of Paediatrics, London SE5 9RS.

Accepted 26 March 1990 first 72 hours of life predict those infants at high risk of dying later of respiratory causes (death after 72 hours age from pulmonary interstitial emphysema, bronchopulmonary dysplasia, or cor pulmonale).

Few previous attempts have been made to identify predictors of late respiratory death. Zarfin et al retrospectively studied a selected group of infants who weighed less than $801 \mathrm{~g}$ at birth up to the age of 28 days, and was able to predict survival with an accuracy of only $79 \% .{ }^{14}$ In a population of infants whose median birth weight was $970 \mathrm{~g}$, Kimble et al found that infants who died consistently required higher ventilator pressures, rates, and oxygen concentrations than infants who survived, although the two groups could not clearly be distinguished by ventilator data alone. ${ }^{15}$ From clinical experience in our nursery we felt that a clear distinction might arise if only those infants who weighed less than $750 \mathrm{~g}$ at birth were considered. Our objective was to determine, in a consecutive series, if this clinical impression could be confirmed. The ventilation requirements of a group of infants were therefore studied to see if we could identify correlates with survival. These correlates were then applied to a separate group to determine their prognostic value. A retrospective design ensured that the study had no influence on clinical management.

\section{Patients and methods}

During the period of the study, British Columbia's Children's Hospital special care nursery was the only tertiary neonatal intensive care unit for an average of more than 42000 deliveries/year in the province. All the infants born in hospital were delivered at the Grace Hospital delivery suite adjacent to the special care nursery. Other infants were referred from hospitals throughout British Columbia.

All infants born alive weighing $<750 \mathrm{~g}$, whose gestational age was 20 weeks or more, and who survived for at least 72 hours, were eligible for the study. We decided to include only those infants whose principal cause of death was respiratory and for whom reliable documentation was available. Exclusion criteria therefore were: death after 72 hours from non-respiratory complications, and admission to the special care nursery after 6 hours of age. We performed two studies; the purpose of the first was to generate criteria that clearly distinguished survivors from infants who died later of respiratory causes, and that of the second was to test the criteria in a separate group of consecutive births.

\section{FIRST STUDY}

In the first study we examined data from 115 
infants born between 1 January 1985 and 31 December 1986,111 of whom $(97 \%)$ were born in the hospital and four of whom (3\%) were referred. Fifty three of those born in hospital (48\%) died in the delivery suite. Twenty eight of the remaining 62 infants who were admitted to the special care nursery died before they were 72 hours old. The 34 infants $30 \%$ of the initial 115) were still alive at 72 hours fulfilled the entry criteria. Three who died after 72 hours of non-respiratory causes (two of sepsis and one of a large intracerebral haemorrhage) were excluded from analysis. The remaining 31 infants, 21 survivors and 10 who subsequently died from respiratory complications, were studied in detail.

\section{SECOND STUDY}

In the second study we examined 60 infants born between 1 January 1987 and 31 December 1987,58 of whom $(97 \%)$ were born in the hospital and two of whom (3\%) were referred. Twenty two (38\%) infants died in the delivery suite. Nine of the remaining 38 infants who were admitted to the special care nursery died before they were 72 hours old. Twenty infants (48\% of the initial 60 ) who were still alive at 72 hours fulfilled the entry criteria. Two who died after 72 hours of non-respiratory causes (one from sepsis and one from a large intracerebral haemorrhage) were excluded from analysis. The remaining 27 infants, 13 survivors and 14 who subsequently died from respiratory complications, were studied in detail.

\section{VENTILATOR MANAGEMENT}

Babies were initially ventilated with a positive end expiratory pressure of $3-5 \mathrm{~cm} \mathrm{H}_{2} \mathrm{O}$ and at the lowest peak inspiratory pressure that produced clinically adequate chest expansion. The inspiratory time was usually set at 0.5 seconds but the initial ventilator rate varied. Settings were subsequently adjusted to produce an arterial carbon dioxide pressure $\left(\mathrm{PaCO}_{2}\right)$ in the range of $4 \cdot 7-6.0 \mathrm{kPa}$ and the arterial oxygen pressure $\left(\mathrm{PaO}_{2}\right)$ in the range of $8 \cdot 0-10 \cdot 7 \mathrm{kPa}$. The Sechrist model IV-100, the Bear Cub BP2001, or the Bourns BP200 ventilator was used. No infant in either study received surfactant.

\section{SOURCES OF DATA}

Clinical details of the obstetric and neonatal course were transferred from the medical records on to standardised forms. Gestational age was determined from the date of the mother's last menstrual period or, if this was not known, by the result of the early obstetric ultrasound scan. The neonatologist's assessment was used where this differed from other estimates of gestational age by more than two weeks $(n=1)$ and where other estimates were not available $(n=6)$. In our nursery ventilator measurements are routinely recorded on to flow charts at the time of blood gas sampling. From these charts we abstracted simultaneous values of fractional inspired oxygen $\left(\mathrm{F}_{\mathrm{I}} \mathrm{O}_{2}\right)$, peak inspiratory pressure, blood gas values, and site of blood sampling, obtained nearest to the following ages (hours) and within the range stated in parentheses $6(2), 12(2), 18(3), 24(3), 36$ (4), 48 (4), and $72(8)$. The follow up clinic records were examined in order to find out the current clinical condition of infants in the first population.

For the first study changes on the initial chest radiograph (taken at $1.8(0.7)$ hours) were graded by a consultant paediatric radiologist who was unaware of the clinical outcome according to the following classification: grade $1=$ clear; 2 =mild granularity, with or without air bronchograms; 3=granularity or haziness that obscured the heart border, with or without air bronchograms; and $4=$ diffuse opacity. The presence of pneumothorax or pulmonary interstitial emphysema, or both, on any film taken during the first 72 hours of life was noted.

\section{ANALYSIS OF DATA}

Peak inspiratory pressure was used as an index of ventilation requirement and arterial:alveolar oxygen ratio as an index of gas exchange. ${ }^{16}$ In the first group, survivors were compared with infants who died later of respiratory causes to find out whether the two groups could be separated on the basis of their peak inspiratory pressure requirement at any of the age intervals reviewed. We chose the 95th centile peak inspiratory pressure requirement (defined as the value of peak inspiratory pressure that was more than that required by $95 \%$ of the survivors) as a cut off value. Only after this cut off was established were peak inspiratory pressure requirements examined in the infants who died later of respiratory causes.

In the first study, arterial:alveolar oxygen ratios were calculated when arterial blood gas values were available (193 of the 217 blood gas results reviewed). The following equation was used:

$$
\begin{gathered}
\text { arterial:alveolar oxygen ratio }=\mathrm{PaO}_{2} / \\
\left(713 \times \mathrm{F}_{\mathrm{I}} \mathrm{O}_{2}\right)-\left(\mathrm{RQ} \times \mathrm{PaCO}_{2}\right)
\end{gathered}
$$

The respiratory quotient $(\mathrm{RQ})$ was taken as $\mathbf{1} \cdot \mathbf{0}$. This was justified because energy is derived from the using up of glycogen stores and from carbohydrate given during the first 72 hours of life. As with peak inspiratory pressure requirements, the 95th centile arterial:alveolar oxygen ratio (defined as the value of arterial:alveolar oxygen ratio that was less than that of $95 \%$ of survivors) was chosen as a cut off point. Values in the infants who died later of respiratory causes were then examined.

\section{Results}

FIRST STUDY

The birth weights, gestational ages, and sex distribution of all the infants who were potentially eligible for the study at the time of birth or transfer to the special care nursery are shown in table 1. As expected, infants who died in the delivery suite were extremely small and immature. Infants who died early (less than 72 hours old) or later (over 72 hours old) tended to have lower birth weights than those who survived to be discharged. During the study period no 
Table 1 Birth weights, gestational ages, and sex distribution in the two groups

\begin{tabular}{|c|c|c|c|c|}
\hline & Total No & No of boys & $\begin{array}{l}\text { Mean (range) } \\
\text { birth weight } \\
(\mathrm{g})\end{array}$ & $\begin{array}{l}\text { Mean (range) } \\
\text { gestational age } \\
\text { (weeks) }\end{array}$ \\
\hline $\begin{array}{l}\text { First study: } \\
\text { Live births in hospital } \\
\text { Live births from elsewhere } \\
\text { Died in labour and delivery room } \\
\text { Total admissions } \\
\text { Early deaths } \\
\text { Survivors } \\
\text { Late deaths from respiratory causes }\end{array}$ & $\begin{array}{r}111 \\
4 \\
53 \\
62 \\
28 \\
21 \\
10\end{array}$ & $\begin{array}{r}52 \\
2 \\
26 \\
28 \\
16 \\
8 \\
3\end{array}$ & $\begin{array}{l}542(260-740) \\
548(450-600) \\
450(260-730) \\
621(420-740) \\
609(440-720) \\
660(570-740) \\
590(420-720)\end{array}$ & $\begin{array}{l}23 \cdot 6(20-33) \\
23 \cdot 3(23-24) \\
22 \cdot 1(20-27) \\
24 \cdot 8(22-33) \\
24 \cdot 5(22-33) \\
25 \cdot 0(23-28) \\
25 \cdot 6(24-28)\end{array}$ \\
\hline $\begin{array}{l}\text { Second study: } \\
\text { Live births in hospital } \\
\text { Live births from elsewhere } \\
\text { Died in labour and delivery room } \\
\text { Total admissions } \\
\text { Early deaths } \\
\text { Survivors } \\
\text { Late deaths from respiratory causes }\end{array}$ & $\begin{array}{r}58 \\
2 \\
22 \\
38 \\
9 \\
13 \\
14\end{array}$ & $\begin{array}{r}31 \\
0 \\
9 \\
22 \\
5 \\
6 \\
10\end{array}$ & $\begin{array}{l}576(200-745) \\
644(560-727) \\
447(200-700) \\
654(360-745) \\
601(360-690) \\
684(480-745) \\
666(560-730)\end{array}$ & $\begin{array}{l}24 \cdot 2(20-33) \\
24 \cdot 0(24-24) \\
22 \cdot 0(20-29) \\
25 \cdot 4(23-33) \\
24 \cdot 2(23-28) \\
26 \cdot 2(24-33) \\
25 \cdot 5(24-28)\end{array}$ \\
\hline
\end{tabular}

infant of gestational age of less than 23 weeks or having a birth weight of less than $570 \mathrm{~g}$ survived. The sex distribution among those who survived and those who died later of respiratory causes was similar. Of the 31 study infants, 21 survived until discharge and 10 died from respiratory complications. The median length of survival among those who died was 31.5 days (range 4-289 days); four survived for four months or longer. The 21 babies who survived (18\% of the initial population of 115 ) were discharged at a median age of 140 days, range 54-417 days. All had been seen at the Children's Hospital follow up clinic at a mean corrected age of 15 months (range 8-21). Twenty infants were still alive; one had died of a cause not related to prematurity (metastatic rhabdomyosarcoma of the mandible).

Thirty three of the 34 infants who survived until they were 72 hours of age were ventilated throughout that period. One infant was electively extubated at 12 hours of age and discharged alive. There was more scatter in peak inspiratory pressure values among the infants who died later of respiratory complications than among the survivors, suggesting that their ventilation requirements were more unstable. The median peak inspiratory pressure values were lower among survivors than those who died later, and the two groups became more distinct with increasing age (fig 1). The 95th centile peak inspiratory pressure requirement in this group was $24 \mathrm{~cm} \mathrm{H}_{2} \mathrm{O}$ at 6 hours age and decreased to $16 \mathrm{~cm} \mathrm{H} \mathrm{H}_{2} \mathrm{O}$ by 72 hours age (fig 1 (B)). At the 48 and 72 hour time points only one of 10 infants who died later had a peak inspiratory pressure requirement below the 95th centile and (by definition) only one of the 21
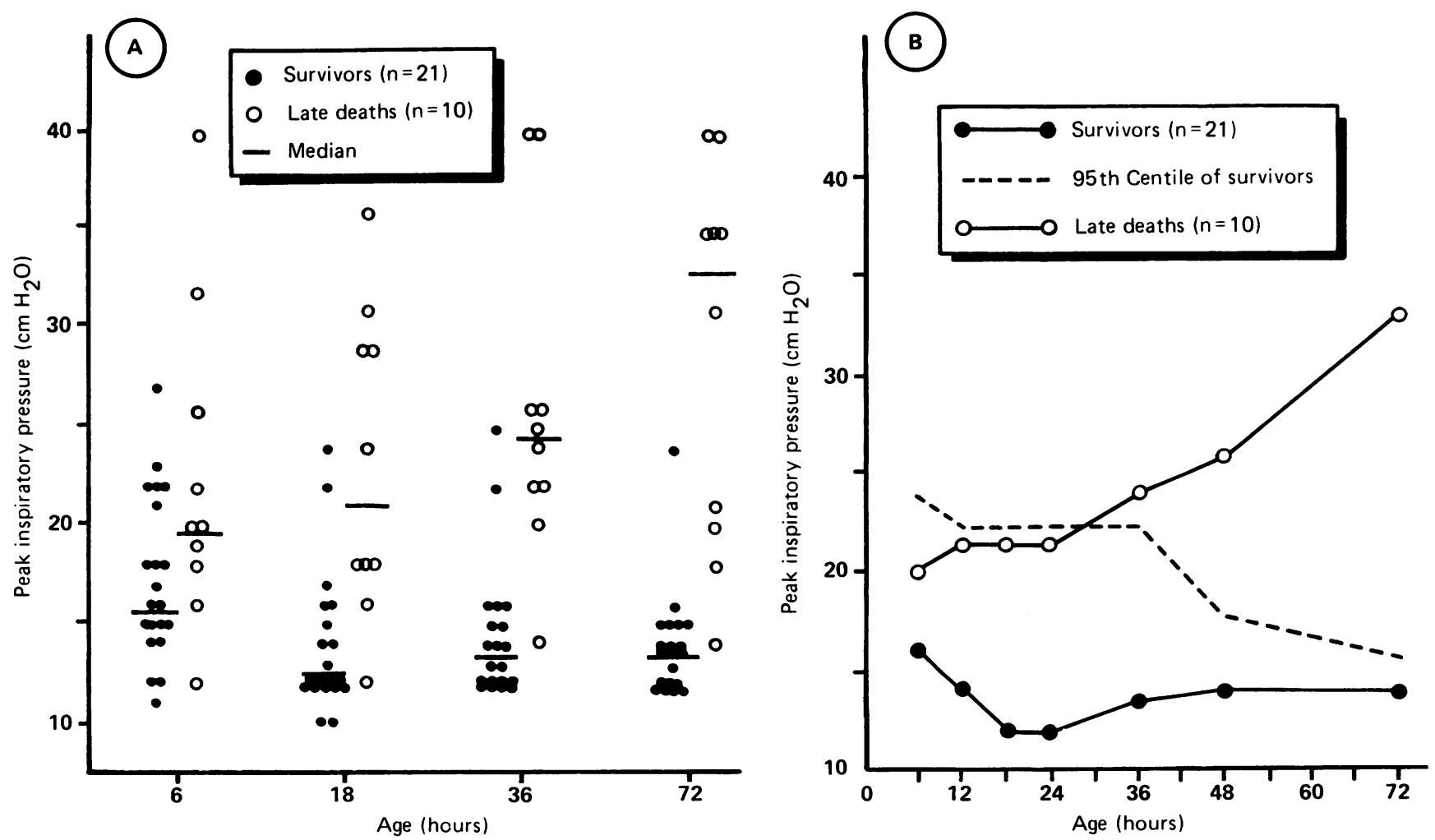

Figure $1(A)$ The range and distribution of peak inspiratory pressure requirements during the first 72 hours of life in survivors and infants who died later of respiratory causes in the first study. For clarity, values at 12, 24, and 48 hours have been omitted. Figure $1(B)$ The median peak inspiratory pressure requirements in the survivors and those that died later, and the 95 th centile peak inspiratory pressure for the survivors. One survivor was extubated before 18 hours. 
survivors had a peak inspiratory pressure requirement above the 95th centile. The 95th centile therefore seemed to be a good discriminant for survival among infants in the first study group.

There was a wide distribution in the values of arterial:alveolar oxygen ratio: $0 \cdot 1-0.8$ among survivors and $0.05-0.4$ among those who died later. The two groups became more distinct with increasing age, but not to the same degree as was seen with the peak inspiratory pressure values. The 95th centile arterial:alveolar oxygen ratio varied between 0.1 and 0.2 during the first 24 hours, and then remained stable around $0 \cdot 19$ until 72 hours of life. By 48 hours of life, three of nine infants (33\%) among those who died later and for whom data was available had an arterial:alveolar oxygen ratio above the 95th centile. One survivor (by definition) had an arterial:alveolar oxygen ratio below the 95th centile. Thus the 95th centile arterial:alveolar oxygen ratio was not as good a discriminant for survival as the 95th centile peak inspiratory pressure requirement. For this reason we chose the 95th centile peak inspiratory pressure requirement for assessment in the second study.

\section{SECOND STUDY}

We applied the survival criteria of a peak inspiratory pressure requirement below the 95th centile by 72 hours of life, established in the first study, to 27 infants born between 1 January 1987 and 31 December 1987. Their birth weights, gestational ages, and sex distribution (table 1) were similar to those in the first study. The peak inspiratory pressure requirements at 72 hours of the 13 infants who survived (median at discharge 124 days) and those of the 14 infants who died later of respiratory causes (median age of death 138 days) are shown in fig 2. Of 13 infants whose peak inspiratory pressure requirement crossed and remained above the 95th centile during the first 72 hours of life, 12 died of respiratory complications. Thus the predictive value for late respiratory death of a peak inspiratory pressure requirement above the 95th centile was $92 \%$ ( $p=0.00017$, two tailed Fisher's exact test). In contrast, $12(80 \%)$ of 15 infants whose peak inspiratory pressure requirement

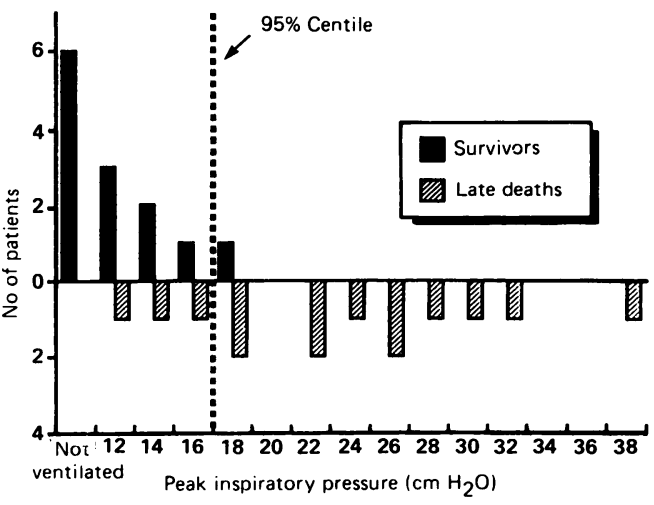

Figure 2 Peak inspiratory pressure requirements at 72 hours for the 13 survivors (solid bars) and the 14 infants that died for the 13 survivors (solid bars) and the 14 infants that died
later of respiratory causes in the second study. The 95th centile peak inspiratory pressure requirement for infants in the first study is also shown.
Table 2 Radiological changes

\begin{tabular}{|c|c|c|c|}
\hline & $\begin{array}{l}\text { No (\%) } \\
\text { of early } \\
\text { deaths }\end{array}$ & $\begin{array}{l}\text { No (\%) } \\
\text { of survivors }\end{array}$ & $\begin{array}{l}\text { No (\%) of } \\
\text { late deaths } \\
\text { from respiratory } \\
\text { causes }\end{array}$ \\
\hline \multirow{2}{*}{$\begin{array}{l}\text { Radiographic changes: } \\
\text { Grade } 1 \\
\text { Grade } 2 \\
\text { Grade } 3 \\
\text { Grade } 4 \\
\text { Pulmonary inter- } \\
\text { stitial emphysema } \\
\text { Pneumothorax } \\
\text { No radiograph taken }\end{array}$} & $\begin{aligned} 3 & (11) \\
6 & (21) \\
15 & (54) \\
1 & (4)\end{aligned}$ & $\begin{aligned} & 12(57) \\
& 8(38) \\
& 0 \\
& 0\end{aligned}$ & $\begin{array}{ll}2 & (15) \\
1 & (8) \\
7 & (54) \\
2 & (15)\end{array}$ \\
\hline & $\begin{array}{r}16(57) \\
8(29) \\
3(11)\end{array}$ & $\begin{array}{l}3(14) \\
2(10) \\
1(5)\end{array}$ & $\begin{aligned} 10 & (77) \\
3 & (23) \\
1 & (8)\end{aligned}$ \\
\hline ota & $28(100)$ & $21(100)$ & $13(100)$ \\
\hline
\end{tabular}

remained below the 95 th centile, survived and three $(20 \%)$ died.

In the first study pulmonary interstitial emphysema, pneumothorax, or grade 3 or grade 4 changes or more on the initial chest radiograph were more likely to be present in infants who died than in infants who survived (table 2). In addition, mean (SD) $\mathrm{PaCO}_{2}$ was lower among survivors, being $4 \cdot 1(1 \cdot 2), 4.5$ $(0 \cdot 7), 4 \cdot 8(1 \cdot 4)$, and $4.9(1 \cdot 1) \mathrm{kPa}$ than among infants who died later, among whom the values were $5 \cdot 7(1.5), 5 \cdot 7(0.8), 7 \cdot 6(2 \cdot 6)$, and $5 \cdot 7(1 \cdot 7)$ at $6,18,36$, and 72 hours, respectively. Similarly, in the second study mean (SD) $\mathrm{PaCO}_{2}$ was lower among survivors, being $4 \cdot 7$ $(0.8), 4.7(1.0), 5 \cdot 1(0.7)$, and $5.3(0.8) \mathrm{kPa}$ compared with $4.9(1.0), 5.7(1.2), 6.3(1.5)$, and $6.7(1.9)$ at $6,18,36$, and 72 hours, respectively. These observations suggest that differences in outcome were a result of variation in the severity of early lung disease (before the age of 72 hours), rather than more aggressive ventilator management resulting in more barotrauma among those that died later of respiratory causes.

\section{Discussion}

The results of this study suggest that in infants weighing less than $750 \mathrm{~g}$ at birth who survive the first 72 hours of life, ventilator requirements may predict late respiratory death from respiratory causes. The more pressure and oxygen required by very tiny babies the worse is the outcome; our findings support this impression but, in addition, we have identified and validated specific early predictors of later respiratory death. Using this method it has been possible to make a clear distinction between survivors and those who will die later. Our findings are dependent on the style of management, however, so should not be directly extrapolated to other intensive care nurseries. Although styles of management may differ elsewhere, our method of validating early predictors of late respiratory death could be applied in other centres.

It would be reasonable to expect treatment with surfactant to alter early peak inspiratory pressure requirements in infants weighing less than $750 \mathrm{~g}$, so our findings cannot be extrapolated to infants being treated in this way.

Because follow up showed that survival until discharge corresponded with long term survival, survival until discharge was a valid end point to use in this study. 
Our finding, that peak inspiratory pressure requirement was of more value than arterial: alveolar oxygen ratio in predicting late respiratory death, confirms those of Simbruner et al. ${ }^{17}$ They found that early measurements of compliance predicted outcome in infants with respiratory distress syndrome. In addition, arterial:alveolar oxygen ratio is dependent on factors other than the pathology of the lung parenchyma, such as pulmonary perfusion and the shunting of blood between the pulmonary and systemic circulations.

In general, predictive information is useful to those managing infants who weigh less than $750 \mathrm{~g}$ at birth in the selection, or stratification by prognosis, of a study group in which it might be ethically justified to try new treatments. In making decisions of clinical management or in answering parents questions regarding individual patients, however, caution must be exercised. This is because we studied only a small number of infants in a single hospital. In addition, no comment can be made about infants whose peak inspiratory pressure requirement goes above then returns below the 95th centile, as no such cases were seen.

We would have expected the mean $\mathrm{PaCO}_{2}$ to be higher in survivors than in those that died later of respiratory causes, at least during the early hours of life, if the different outcomes could be explained by more aggressive ventilator management of the latter infants. The reverse was the case, however, suggesting that the severity of lung disease is the main determinant of outcome. Radiological findings supported this supposition. As in previous studies, the presence of pulmonary interstitial emphysema in extremely low birthweight infants indicated a poor prognosis. ${ }^{18}$

In summary we have described a method for validating early predictors of late respiratory death in infants who weighed $<750 \mathrm{~g}$ at birth. In our nursery, the peak inspiratory pressure requirement in the first 72 hours of life clearly distinguished survivors from those who died later. Peak inspiratory pressure requirement seemed to reflect the severity of the initial lung disease rather than the effect of ventilator management. We thank Dr Betty Wood for interpreting the radiographs, and
Dr MF Whitfield for his advice and for supplying the follow up Dr M
data.

1 Hack M, Fanaroff AA. Special report. Changes in the delivery room care of the extremely small infant $(<750 \mathrm{~g})$ : effects on morbidity and outcome. N Engl f Med 1986;314

2 Saigal S, Rosenbaum P, Stoskopf B, Sinclair JC. Outcome in infants $501-1000 \mathrm{gm}$ birth weight delivered to residents of the McMaster Health Region. $\mathcal{F}$ Pediatr 1984;105:969-76.

3 Orgill AA, Ashbury J, Bajuk B, Yu VYH. Early development of infants $1000 \mathrm{~g}$ or less at birth. Arch Dis Child 1982;57: 823-7

4 Britton SB, Fitzhardinge PM, Ashby S. Is intensive care justified for infants weighing less than $801 \mathrm{~g}$ at birth? $\mathcal{F}$ Pediat 1981;99:937-43.

5 Toshiko H, Epcar JT, Walsh AZ, et al. Survival and outcome of infants 501-750 g: A six year experience. $\mathcal{F}$ Pediatr 1983; 102:741-8.

6 Buckwald S, Zorn WM, Egan E. Mortality and follow up data for neonates weighing 500-800 gm at birth. Am $\mathcal{f} D$ is data for neonates weigh

7 Yu VYH, Loke HL, Bajuk B, Szymonowicz W, Orgill AA, Ashbury J. Prognosis for infants born at 23 to 28 weeks' Ashbury J. Prognosis for infants born

8 Sandhu B, Stevenson RC, Cooke RWI, Pharoah POD. Cost of neonatal intensive care for very low birth weight infants. Lancet 1986;i:600-3.

9 Hack M, Fanaroff AA. How small is too small? Considerations in evaluating the outcome of the tiny infant. Clin Perinatol 1988;15:773-88.

10 Tudehope DI, Lee W, Harris F, Addison C. Cost analysis of neonatal intensive and special care. Aust Paediatr $\mathcal{Y} 1989$; 25:61-5.

11 Stinson R, Stinson P. On the death of a baby. $\mathcal{F}$ Med Ethics 1981;7:5-18.

12 Marshall RE, Kasman C. Burnout in the neonatal intensive care unit. Pediatrics 1980;65:1161-5.

13 Vasa R, Vidyasagar D, Winegar A, Peterson P, Spellacy WN. Perinatal factors influencing the outcome of 501 to $1000 \mathrm{gm}$ newborns. Clin Perinatol 1986;13:267-84.

14 Zarfin J, Van Aerde J Perlman M, Pape K, Chipman M. Predicting survival of infants of birth weight less than 801 Predicting survival of infants of birth

g. Crit Care Med 1986;14:768-72.
15 Kimble K, Ariagno RL, Stevenson DK, Sunshine P. PredictKimble K, Ariagno RL, Stevenson DK, Sunshine P. Predict-
ing survival among ventilator-dependent very low birth weight infants. Crit Care Med 1983;11:182-5.

16 Gilbert R, Keighley JF. The arterial/alveolar oxygen tension ratio. An index of gas exchange applicable to varying inspired oxygen concentrations. Am Rev Respir Dis 1974; 109:142.

17 Simbruner G, Coradello H, Lubec G, Pollak A, Salzer H. Die Compliance des respiratorischen Systems bei gesunden und respiratorisch erkrankten Neugeborenen in den ersten Levensstunden und ihr prognostischer Wert fur den Einsatz von Atemhilfen, Klin Padiatr 1980;192:415-8.

18 Hart SM, McNair M, Gamsu HR, Price JF. Pulmonary interstitial emphysema in very low birthweight infants. Arch Dis Child 1983;58:612-5. 